\title{
The conjugative plasmid pSG5 from Streptomyces ghanaensis DSM 2932 differs in its transfer functions from other Streptomyces rolling-circle-type plasmids
}

\author{
Ruth-Maria Maas, † Jörg Götz, Wolfgang Wohlleben and Günther Muth
}

Mikrobiologie/Biotechnologie, Universităt Tübingen, Auf der Morgenstelle 28, D-72076 Tübingen, Germany
Author for correspondence: Günther Muth. Tel: +497071 29 74637. Fax: +497071 295979. e-mail : gmuth@molbio.biol.biologie.uni-tuebingen.de

Keywords: conjugation, Streptomyces plasmids, rolling-circle-replication, pock formation

\section{INTRODUCTION}

Conjugative gene transfer in bacteria is a very conserved process of acquiring new traits. The same mechanistic principle is realized in phylogenetically different bacteria, allowing horizontal gene transfer even between distantly related organisms. The central steps in conjugation are: generation of cell-to-cell contact (Manning \& Achtmann, 1979), initiation of conjugative DNA metabolism (Kingsman \& Willetts, 1978; Pansegrau et al., 1990), formation of a mating pore (Haase et al., 1995) and transfer of a single-stranded plasmid molecule (Gross \& Caro, 1966).

Conjugation depends on the presence of conjugative plasmids that carry all the genes necessary to synthesize the whole transfer apparatus. The transfer regions of

†Present address: Institut für Humangenetik, Theoretische Medizin, Universităt des Saarlands, D-66421 Homburg, Germany.

Abbreviations: $\mathrm{HTH}$, helix-turn-helix; RCR, rolling-circle replication.

The EMBL accession number for the sequence reported in this paper is X80774. conjugative plasmids from Gram-negative bacteria are located on rather large DNA fragments which comprise, in the case of the F-plasmid, about $33 \mathrm{~kb}$ and encode 36 genes (Frost et al., 1994). More than half these genes are responsible for synthesis of the so-called sex pili that mediate the cell-to-cell contact. Such pili have not been found in Gram-positive bacteria, where mating pairs can be formed by the production of aggregating substances (Clewell, 1993).

Conjugative DNA metabolism of plasmids from Gramnegative and most Gram-positive bacteria is initiated by a sequence-specific endonuclease (relaxase) that nicks the conjugative plasmid at a specific sequence (oriT), then forms a relaxosome (Pansegrau et al., 1990) and initiates replication and transfer of a single-stranded molecule by a rolling-circle mechanism (Wilkins \& Lanka, 1993; Climo et al., 1996). The single-stranded molecule is transferred to the recipient cell by the action of several plasmid-encoded proteins (Frost et al., 1994). Some of these are hydrophobic proteins, possessing similarity to the secretion apparatus of pathogenicity factors (Weiss et al., 1993) that become integrated into 
the membrane of the donor, probably forming a pore to the recipient cytoplasm.

Conjugative plasmid transfer in Streptomyces is a very efficient process. In a typical mating experiment, up to $100 \%$ of the recipients obtain a plasmid and up to $0.1 \%$ acquire chromosomal markers (Kieser et al., 1982; Bibb \& Hopwood, 1981). The mechanism of plasmid transfer in Streptomyces is completely different from that of plasmids from other bacteria.

The transfer region of a conjugative Streptomyces plasmid, with a size of about 5-6 kb (Hopwood \& Kieser, 1993), is much smaller than the transfer regions of other plasmids. For the best-studied plasmid, pIJ101 (Kieser et al., 1982), it was shown that a single protein (Tra) together with a short sequence $(c l t)$ is sufficient to promote plasmid transfer (Pettis \& Cohen, 1994). Apart from a conserved nucleotide-binding site, the deduced amino acid sequence of Tra shows no similarity to other proteins involved in conjugative transfer but was reported to be similar to the sporulation protein SpolIIE of Bacillus subtilis (Wu et al., 1995) and the cell-division protein FtsK from Escherichia coli (Begg et al., 1995).

In all Streptomyces plasmids that replicate via the rolling-circle-replication (RCR) mechanism, the transfer gene tra is part of a Kil/Kor function. tra is regulated at the transcriptional level by a divergently transcribed gene korA (traR), encoding a transcriptional regulator of the GntR family (Stein et al., 1989; Kataoka et al., 1994b). Unregulated expression of tra is lethal to the host cell. Therefore, tra cannot be cloned without korA. In addition to the transcriptional control of tra expression, Tra seems also to be post-translationally regulated (Pettis \& Cohen, 1996).

Furthermore, Streptomyces plasmid-transfer is a macroscopically visible event and associated with the formation of pocks. Pocks represent growth-retardation zones where aerial mycelium formation is temporally inhibited, and indicate the spreading of the transferred plasmid within the recipient mycelium (Bibb et al., 1977; Kieser et al., 1982). Pock formation requires the activity of spd genes, encoding small hydrophobic proteins. Inactivation of a $s p d$ gene dramatically reduces the pock size (Kieser et al., 1982).

Plasmid pSG5 is a multi-copy RCR plasmid from Streptomyces ghanaensis DSM 2932 (Muth et al., 1988, 1995). Due to its naturally temperature-sensitive replication, derivatives of pSG5 have found wide application as suicide vectors for transposon delivery (Solenberg \& Baltz, 1994; Volff \& Altenbuchner, 1997) and gene disruption and replacement experiments (Muth et al., 1989, 1997; Yu \& Hopwood, 1996).

pSG5 is conjugative, but does not form pocks during the plasmid transfer. The entire pSG5 is transferred to a recipient at a rate of $10^{-1}$, which is typical for Streptomyces plasmids. Derivatives containing only the minimal replicon are still transferred at a rate of about $10^{-4}$. The nucleotide sequence of the pSG5 minimal replicon, encoding a single gene, rep, has recently been published
(Muth et al., 1995). Here we report the complete nucleotide sequence of pSG5 and the functional characterization of the pSG5 transfer functions.

\section{METHODS}

Strains and plasmids. The E. coli strain used for subcloning was XL-1 Blue (Bullock et al., 1987). Streptomyces lividans strains were TK23 and TK64 (Hopwood et al., 1983). Unless indicated otherwise, antibiotics were used in the following concentrations $\left(\mu \mathrm{g} \mathrm{ml}^{-1}\right)$ : kanamycin 50 , spectinomycin 50 , streptomycin 40, thiostrepton (kindly provided by Dr Lucania, Squibb \& Sons, Princeton, NJ, USA) 25. Plasmid pJG4 was generated by ligating EcoRI-digested pUC18 into EcoRIdigested pGM11 (Wohlleben \& Muth, 1993). To construct pJG5, the 4973 bp SphI fragment of pSG5 which encodes the traB gene was inserted into the SphI site of pUC18 and the resulting plasmid was fused with pGM11 via the EcoRI sites. The plasmid pGM19 was constructed by ligating an aphll-tsr cassette into the single StuI site of plasmid pSG5. The $478 \mathrm{bp}$ $\mathrm{Ncol}$ fragment containing the intergenic region between traR and $s p d B 3$ was filled in with Klenow polymerase, subcloned into the Smal site of pUC18 and inserted as a EcoRI-HindIII fragment into $\mathrm{pIJ} 487$ and $\mathrm{pIJ} 486$, resulting in pIJ487-traR and pIJ486-spdB3, respectively. The traB promoter region was cloned as a filled-in $460 \mathrm{bp} \mathrm{SgrAI-MluI} \mathrm{fragment} \mathrm{into} \mathrm{SmaI-}$ digested pUC18 and subsequently as an EcoRI-HindIII fragment into pIJ487 (pIJ487-traB). To investigate regulation of the $t r a B$ promoter by TraR, the $1810 \mathrm{bp} \mathrm{BamHI}$ fragment containing traR was subcloned into pUC18 and the resulting plasmid was subsequently fused via EcoRI with pIJ487-traB, resulting in pJG2. As a control, pIJ487-traB was inserted into the single EcoRI site of pUC18, yielding pJG1.

Sequence analysis. The nucleotide sequence was determined for both strands on an ALF Express (Pharmacia) sequencer using the Sequenase kit (Pharmacia). Subclones were obtained using various restriction enzymes and the Exonuclease III nested deletion kit (Pharmacia). Gaps in the sequence were closed using oligonucleotide primers and internal labelling. Computer programs used for sequence analysis were FASTA (Pearson \& Lipman, 1988), BLAST (Altschul et al., 1990), the Staden package (Staden \& McLachlan, 1982), TMpredict (Hofmann \& Stoffel, 1993) and clustal w (Thompson et al., 1994).

Analysis of the mutant phenotype by Tn 5 mutagenesis. The Tn5 insertions obtained by mutagenizing the bifunctional shuttle plasmid pSW344E (Muth et al., 1988) were localized by restriction mapping and sequence analysis using pSG5-specific primers. Selected plasmids, carrying Tn 5 insertions within the respective genes, were digested with $E c o$ RI and religated to remove the $5.4 \mathrm{~kb}$ pSLE41 (Muth et al., 1988) part of pSW344E. The resulting plasmids, which comprise the total pSG5, carrying the $\mathrm{Tn} 5$ insertion without any further $E$. coli sequences, were used as donors in mating experiments to identify genes affecting conjugal transfer of pSG5.

Promoter-probe experiments. The putative promoter regions were subcloned into the promoter-probe plasmids pIJ486 and pIJ487 (Ward et al., 1986). The cloned pSG5 fragments are summarized in Table 2 . To estimate promoter activity, about $10^{4}$ spores were spotted onto the wells of a 24 -well microtitre plate containing LB agar supplemented with $0,25,50,100$, $200,400,600$ or $800 \mu \mathrm{g}$ kanamycin $\mathrm{ml}^{-1}$ and incubated at $30^{\circ} \mathrm{C}$. Resistance was determined as the kanamycin concentration that allowed growth as a dense lawn. 
Genetic crosses. About $10^{7}$ spores of the plasmid-containing donor S. lividans TK23 (spc-1) were plated together with the same amount of plasmid-free TK64 (pro str-6) spores on SM agar. After $4-5 \mathrm{~d}$ incubation at $30^{\circ} \mathrm{C}$, spores were harvested and serial dilutions were plated on selective agar to estimate the transfer frequencies (measured as transconjugants/ recipients).

\section{RESULTS}

\section{Transfer characteristics of pSG5}

Plasmids pGM19 and pSG5-34, which contain the whole of pSG5, were transferred in S. lividans to a plasmid-free recipient with a rate of about $10^{-1}$ (Table 1 ). The transfer rate of $10^{-4}$, which was previously reported for pSG5 derivatives (Muth et al., 1995), was found to be due to the unstable replication of the bifunctional pSW344E. In particular, when pSW344E carried a Tn5 insertion, the plasmid was lost at high frequencies. pSG5 derivatives, such as pGM9 (Muth et al., 1989), carrying exclusively the minimal replicon which only encodes the rep gene and the plus origin, were still transferred with a frequency of $10^{-4}$.

In contrast to all other conjugative Streptomyces plasmids, the transfer of pSG5 was not associated with the formation of clearly visible pocks, which normally indicate transfer and spreading of the plasmids in the recipient mycelium.

\section{Sequence analysis of pSG5}

The complete nucleotide sequence of pSG5 was determined on both strands. According to the sequence, pSG5 has a size of 12208 bp and a GC content of 68 $\mathrm{mol} \%$. Eleven open reading frames (ORFs) were identified with the codon probability program of the Staden package (Staden \& McLachlan, 1982) and a Strepto- myces codon table (Wright \& Bibb, 1992). Although there was no clear sequence identity, putative functions were proposed for most genes by sequence similarity to other Streptomyces RCR plasmid-encoded proteins (Fig. 1).

Regulatory proteins. traR encodes a transcriptional repressor of the GntR family (Haydon \& Guest, 1991), showing the highest similarity $(56.4 \%$ identity, $236 \mathrm{aa})$ to KorA of pIJ101. A helix-turn-helix (HTH) motif (aa $30-72$ ) is present in its $\mathrm{N}$-terminus. The putative ATG start codon is preceded ( $7 \mathrm{bp}$ ) by a likely ribosomebinding site (RBS), GGAGG. At $11 \mathrm{bp}$ downstream of the TGA stop codon, there is a hairpin structure $\left(-44.3 \mathrm{~kJ} \mathrm{~mol}^{-1}\right)$ with $14 \mathrm{bp}$ in the stem and $7 \mathrm{bp}$ in the loop, which could act as a transcriptional terminator. No tre boxes (Kataoka et al., 1994b), or other repeats that could act as binding sites for the TraR protein, as described for the corresponding region of pSN22 and pJV1 (Servin-Gonzales et al., 1995), were found in front of the pSG5 traR gene.

The $p r g$ gene (putative regulatory gene) is preceded by a likely RBS (GGAGG, 6 bp upstream of ATG) and encodes a putative regulatory protein of 265 aa. Prg possesses an HTH motif at the C-terminus with similarities to the HTH motifs of the regulatory proteins FnrN of Rhizobium leguminosarum (Hernando et al., 1995), HutC protein of Pseudomonas putida (Allison \& Phillips, 1990) and ORFL of the linear pSCL1 plasmid of Streptomyces clavuligerus (Wu \& Roy, 1993). Prg showed no sequence similarity to the KorB regulator of pIJ101 or to the SpdA proteins of pSN22 and pJV1.

Putative spread (spd) genes. The ORF spdB3 encodes a protein of 151 aa with two predicted transmembrane helices (aa 81-102 and 112-130). The C-terminal half of SpdB3 can be aligned $(45.9 \%$ identity) with SpdB3 of pSN22, a 70 aa protein involved in pock formation. A

Table 1. Transfer rates of pSG5 derivatives carrying Tn 5 insertions

\begin{tabular}{|c|c|c|c|}
\hline Name & Inactivated gene & Insertion/deletion & $\begin{array}{c}\text { Transfer } \\
\text { rate }^{*}\end{array}$ \\
\hline pGM19 & ORF106 & Insertion of $t s r$ and $a p b l l$ in StuI site & $10^{-1}$ \\
\hline pGM9 & $\begin{array}{l}\text { prg, } \operatorname{traR}, \\
\operatorname{traB}, \text { ORF193/141, } \\
\text { spdB3/ORF80/spdB2 }\end{array}$ & Deleted & $10^{-4}$ \\
\hline pSW344E $†$ & - & Insertion of pSLE 41 in EcoRI site & $10^{-4}$ \\
\hline pGM12 & prg & Replaced by aphII & $10^{-1}$ \\
\hline pSG5-1 & $s p d B 2$ & $\operatorname{Tn} 5$ insertion & $10^{-2}$ \\
\hline pSG5-22 & $\operatorname{traB}$ & $\operatorname{Tn} 5$ insertion & $10^{-5}$ \\
\hline pSG5-29b & traR & Tn5 insertion & $10^{-2}$ \\
\hline pSG5-34 & prg & $\operatorname{Tn} 5$ insertion & $10^{-1}$ \\
\hline pSG5-41 & $s p d B 2$ & Tn5 insertion & $10^{-3}$ \\
\hline pSG5-17 & ORF193 & Tn5 insertion & $10^{-2}$ \\
\hline
\end{tabular}

* The transfer frequencies represent the mean values of at least four independent crosses. The data differed from experiment to experiment by less than a factor of 10 .

tpSW344E turned out to be highly unstable. 


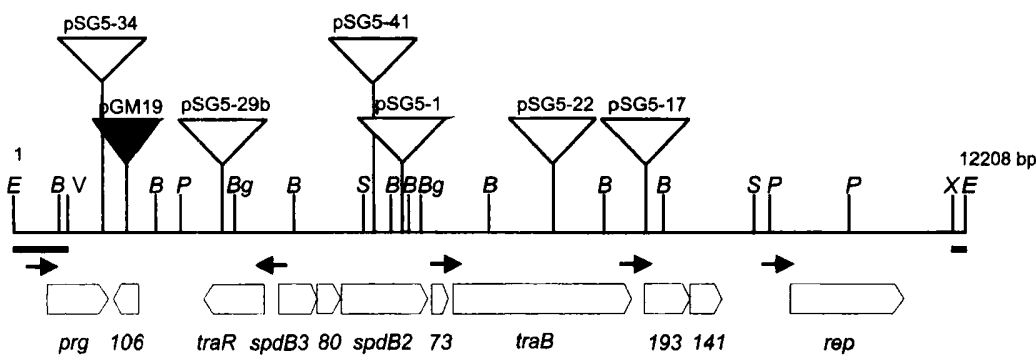

Fig. 1. Restriction map of pSG5 and its overall gene organization. ORFs without known functions are designated by their length in amino acid residues. The positions of insertions used for the characterization of pSG5 are marked by open (Tn5) and filled (tsr, aphII) triangles. The fragment which has been replaced in PGM12 by an aphll cassette is shown as a black line. Regions with promoter activity are indicated by black arrows. Abbreviations: B, BamHI; Bg, Bg/lI; E, EcoRI; P, Pstl; V, EcoRV; S, Sphl; $X$, Xhol.

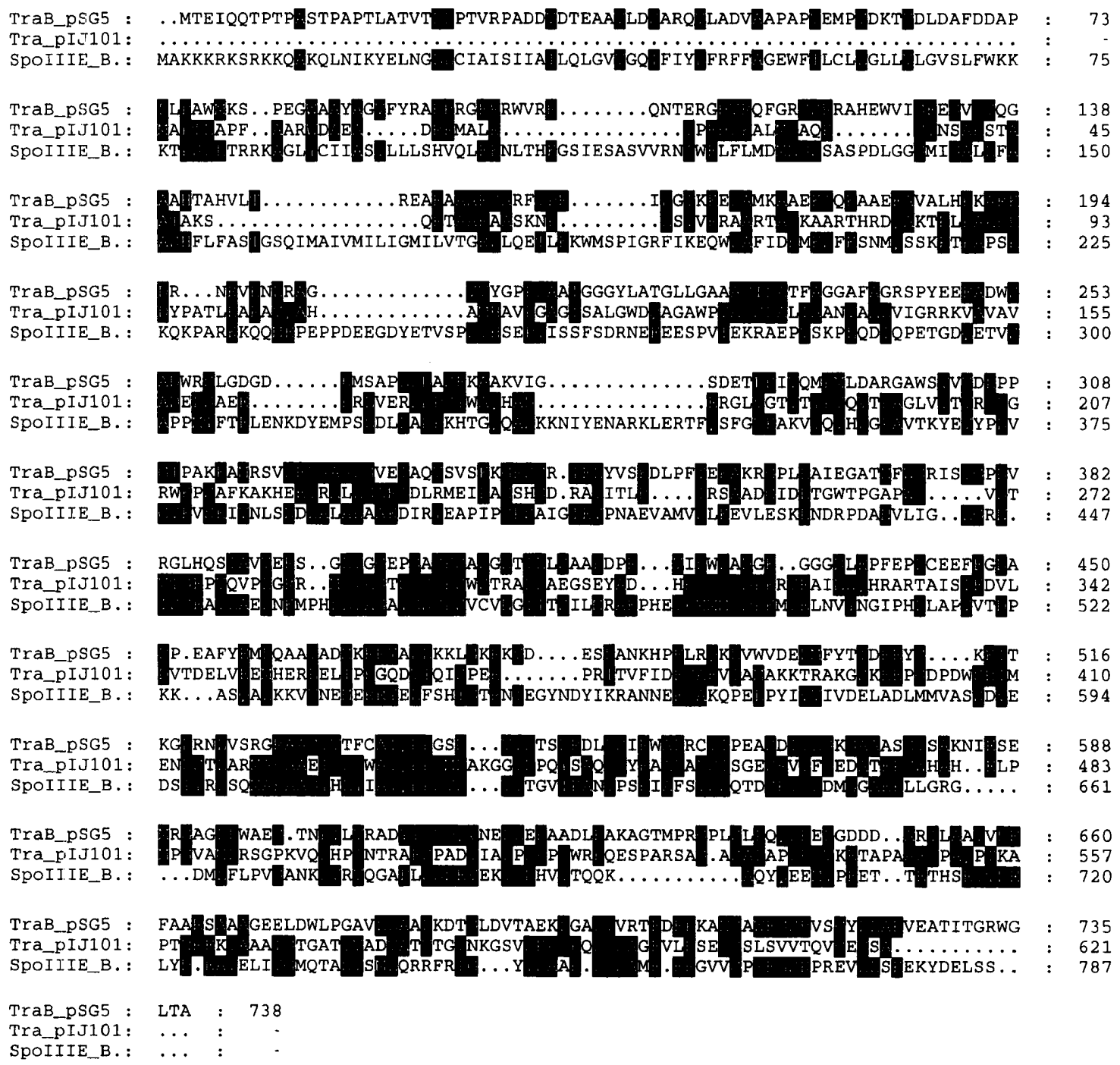

Fig. 2. Alignment of the pSG5 TraB protein with SpollIE of B. subtilis and the Tra protein of plJ101. The pSG5 TraB protein was aligned with the Tra protein of plJ101 and the SpollIE protein of $B$. subtilis. Identical and conservative residues are shown in black.

putative RBS (GGAG) is located $9 \mathrm{bp}$ upstream of the ATG start codon.

The ATG start codon of ORF80 overlaps with the TGA stop codon of $s p d B 3$, indicating translational coupling of these two genes. The deduced protein showed no similarity to other proteins. ORF80 encodes a very hydrophobic protein that contains a predicted trans- 
membrane helix (aa 4-24). The next ORF, spdB2, is probably also translationally coupled to $s p d B 3$ and ORF80, since its start codon overlaps the termination codon of ORF80. The deduced SpdB2 protein consists of $404 \mathrm{aa}$. Its N-terminus possesses similarity to the SpdB2 protein of pJV1 (37.4\% identity, 91 aa overlap) and to the TraI protein of pMEA300 $(22.8 \%$ identity, 372 aa overlap). Furthermore, it has some similarity to the TolA protein $(38.8 \%, 85$ aa overlap) of $E$. coli, which is involved in the uptake of colicin and single-stranded DNA during phage infection. SpdB2 contains four transmembrane helices (96-112, 126-145, 162-180, 188-204) and a possible fifth one with lower significance (279-297). A structure prediction with TMpredict (Hofmann \& Stoffel, 1993) revealed very similar structures for SpdB2 of pSG5, TraI of pMEA300 and SpdB of pIJ101, which had no sequence similarity. The SpdB2 protein of pSG5 has several characteristic repetitive sequences $\left({ }_{4}\right.$ REEKRAD and ${ }_{35}$ AEEKRAD, ${ }_{42}$ AEAKA and ${ }_{48}$ REAKA and ${ }_{53}$ AEAKR, ${ }_{69}$ AKKAA and ${ }_{73}$ AKK$A A$, and many more less conserved ones) in its $\mathrm{N}$ terminus. Similar repeats are also found in the corresponding SpdB2 proteins of $\mathrm{pJV} 1$ and $\mathrm{pSN} 22$, the TraI protein of pMEA300, and the TolA protein of E. coli.

Transfer genes. The deduced TraB protein showed the highest similarity to the SpoIIIE/FtsK family of proteins. It contains a putative nucleotide-binding site (motif $\mathrm{A}$, GEPGAGKS; motif B, hhhhDEFA; Walker et al., 1982) and possesses a predicted transmembrane helix between aa 220 and 240 . The whole TraB protein from pSG5 can be aligned (Fig. 2) with the SpollIE homologous proteins of various Gram-positive and Gram-negative bacteria with the C-terminal half showing the highest similarity (B. subtilis, 23.2\% identity, 328 aa; Mycobacterium tuberculosis, $21 \cdot 6 \%$, 334 aa; E. coli, $21 \cdot 1 \%, 218$ aa). The similarities to Streptomyces Tra proteins were: $27 \cdot 3 \%$ identity, 205 aa overlap, to Spi from pSA1.1; $30.7 \%(192 \mathrm{aa})$ to TraSA from pSAM $; 20.9 \%$ (239 aa) to $\operatorname{TraB}$ from $\mathrm{pSN} 22 ; 27 \cdot 1 \%$ (192 aa) to $\mathrm{TraB}$ from pJV1; $21.8 \%$ (524 aa) to Tra from pIJ101; and $22.5 \%$ (581 aa) to the TraJ protein of pMEA300.

ORFs without known function. ORFs 193/141 show translational coupling. They encode proteins of 193 and 141 aa residues, respectively. ORF106, encoding a protein of 106 residues, is transcribed in the opposite direction. ORF73 is located between $s p d B 2$ and tra. All these ORFs have a codon usage typical for Streptomyces proteins but do not possess any striking features or similarity to proteins deposited in databases.

\section{Gene organization of the transfer region}

All the genes, except traR (and a small ORF), were transcribed in the same direction as rep (Muth et al., 1995). The gene organization of pSG5 differs from that of all other Streptomyces RCR plasmids. In contrast to pIJ101, pSN22, pJV1 and pSAM2, which all carry the spd genes downstream of $\mathrm{tra}$ forming one transcription unit, the putative spd genes of pSG5 are located upstream of $\operatorname{traB}$ (Fig. 1).

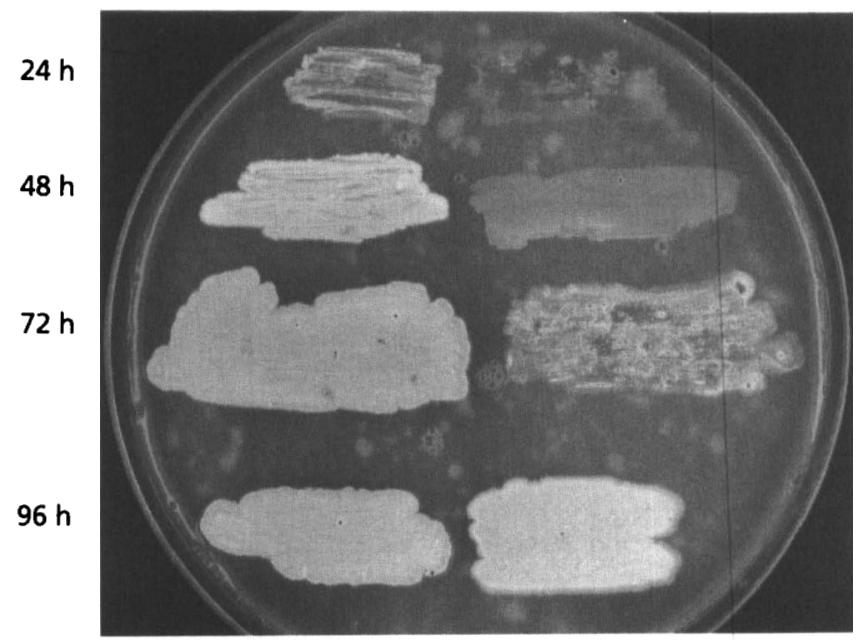

Fig. 3. Retarded sporulation of $S$. lividans conferred by unregulated expression of the pSG5 traB gene. S. lividans TK23/JG4 (control, left) and S. lividans TK23/JG5 (carrying traB, right) were grown on SM agar for $24,48,72$ and $96 \mathrm{~h}$, respectively. After $2 \mathrm{~d}$ on $\mathrm{SM}$ agar $S$. lividans carrying the control plasmid had produced aerial mycelium and spores, but no aerial mycelium formation was observed with $S$. lividans carrying pJG5. After $4 \mathrm{~d}$ incubation both strains had sporulated.

\section{tra $B$ is the main transfer gene}

Selected pSG5 derivatives carrying deletions or Tn5 insertions were analysed with regard to their transfer properties to identify genes that are involved in the conjugal transfer of pSG5 (Table 1). While inactivation of prg (pGM12, pSG5-34), traR (pSG5-20, pSG5-29b), spdB2 (pSG5-41, pSG5-1) and ORF193/141 (pSG5-17) had little or no effect on the transfer of the respective derivative, a $\mathrm{Tn} 5$ insertion within $\operatorname{traB}$ reduced transfer by a factor of 10000 to a rate of $10^{-5}$. This is the same order of magnitude as obtained with pGM9, carrying only the pSG5 minimal replicon without any transfer functions (Muth et al., 1995).

\section{The tra gene of PSG5 is not a kill function}

To analyse whether the $\operatorname{tr} B$ gene of pSG 5 constitutes a kill function, as described for the corresponding genes of other Streptomyces RCR plasmids (Kendall \& Cohen, 1987), the 4973 bp SpbI fragment (Fig. 1) containing the complete traB gene (but not the traR or prg gene) of pSG5 was cloned into a bifunctional pGM11 derivative (pJG5). The resulting plasmid could be introduced into $S$. lividans without interfering with viability. However, on soya/mannitol (SM) agar, sporulation of the traBcarrying strain was retarded. S. lividans carrying the control plasmid pJG4 began to form aerial mycelium and to sporulate after $1 \mathrm{~d}$; sporulation was complete after $3 \mathrm{~d}$. However, $S$. lividans carrying pJG5 started to develop aerial mycelium only after $3 \mathrm{~d}$. Complete sporulation of $S$. lividans carrying pJG5 was observed after $4-5 \mathrm{~d}$ incubation (Fig. 3). 
Table 2. Kanamycin resistance mediated by the putative promoter regions of pSG5 genes

\begin{tabular}{|c|c|c|}
\hline Plasmid* & Cloned fragment & $\begin{array}{c}\text { Kanamycin resistance } \\
\left(\mu \mathrm{g} \mathrm{ml}^{-1}\right)\end{array}$ \\
\hline plJ487-traB & $S g r \mathrm{AI}_{5398}-M l u \mathrm{I}_{5858}$ & 600 \\
\hline pIJ487-traR & $\mathrm{Ncol}_{3661}-\mathrm{NcoI}{ }_{3138}$ & 400 \\
\hline plJ486-spdB3 & $\mathrm{NcOI}_{3138}{ }^{3001}-\mathrm{NcoI}_{3661}$ & $<25$ \\
\hline plJ487-rep & SalI $_{9556}-\mathrm{PmaCI}_{8974}$ & 100 \\
\hline pl J487-ORF193 & $\mathrm{BamHI}_{7613}-\mathrm{BamHI}_{8337}$ & 50 \\
\hline pl J487-prg & $E c o I_{1}-E c o R V_{699}$ & 200 \\
\hline pJG1 & $\operatorname{SgrAI} I_{5398}-M l u I_{5858}$ & 600 \\
\hline pJG2 & $S g r \mathrm{AI}_{5398}-M l u \mathrm{I}_{5858}, B a m \mathrm{HI}_{3673}-B a m \mathrm{HI}_{1863}$ & $<15$ \\
\hline
\end{tabular}

"All fragments were cloned into the promoter-probe plasmids pIJ486 or pIJ487 (Ward et al., 1986).

Plasmids pJG1 and pJG2 were bifunctional plasmids, carrying in addition pUC18.

\section{The putative spd genes of pSG5 are not transcribed}

To identify promoter activity, the upstream regions of the identified ORFs were subcloned into the promoterprobe plasmids pIJ487 and pIJ486. Promoter strength was measured as resistance level against kanamycin (Table 2). The upstream regions of ORF193, rep, prg and $t r a B$ mediated resistances of $50,100,200$ and $600 \mu \mathrm{g}$ $\mathrm{ml}^{-1}$, respectively (Table 2 ). However, the $478 \mathrm{bp} \mathrm{NcoI}$ fragment, which contained the intergenic region between traR and $s p d B 3$, showed promoter activity $(400 \mu \mathrm{g}$ $\mathrm{ml}^{-1}$ ) only when inserted into pIJ487 (direction of traR transcription). The same fragment inserted into pIJ486 (direction of $s p d B 3$ transcription) revealed no promoter activity, thus indicating that the probably translationally coupled $s p d B 3 /$ ORF $80 / s p d B 2$ genes of pSG5 are not expressed.

\section{The traB promoter is regulated by TraR}

With the exception of the integrative pSAM2 plasmid, the main transfer gene traA/B of the Streptomyces RCR plasmids is regulated by a divergently transcribed regulatory gene $\operatorname{traR}(\operatorname{kor} A$ ). In all cases the promoter regions of traR and $\operatorname{tra} A / B$ overlap. Since the corresponding genes of pSG5 show a different organization and are not located next to each other, we examined whether TraR influences $t r a B$ expression. Unregulated expression of the $t r a B$ promoter in the promoter-probe plasmids pIJ487-traB and pJG1 mediated a kanamycin resistance of $600 \mu \mathrm{g} \mathrm{ml}^{-1}$. If the TraR-encoding fragment was inserted into pJG1 (pJG2), the resistance level dropped to $<15 \mu \mathrm{g} \mathrm{ml} \mathrm{I}^{-1}$, demonstrating repression of the $t r a B$ promoter by TraR (Table 2 ).

\section{DISCUSSION}

Several Streptomyces RCR plasmids have been sequenced in their entirety (Kendall \& Cohen, 1988; Hagège et al., 1993; Kataoka et al., 1994a; ServinGonzales et al., 1995). Homology in the replicationinitiator protein assigns these plasmids to the pC194 family (Muth et al., 1995). In these plasmids, all genes involved in the conjugative transfer form one operon which is regulated by a divergently transcribed regulatory gene. The $s p d$ genes, involved in pock formation by an unknown mechanism, are located downstream of the main transfer gene in pIJ101 (Kendall \& Cohen, 1987), pSN22 (Kataoka et al., 1994a), pJV1 (ServinGonzales et al., 1995) and pSAM2 (Hagège et al., 1993). Although no pocks are formed during the transfer of pSG5 derivatives, sequence analysis of pSG5 revealed the presence of three genes exhibiting some sequence similarity to Streptomyces Spd proteins and possessing the structural characteristics of $s p d$ genes. They encode very hydrophobic proteins, possess several predicted transmembrane helices and are organized within one operon with the genes most likely translationally coupled.

The SpdB2 protein of pSG5 carries several repetitive sequences. Such repetitive sequences are also present in the SpdB2 proteins of pSN22 (RERER $5 \times$ ) and pJV1 (RERQE $5 \times$ ), and in the TraI protein (RREA $6 \times$ ) which is involved in transfer and pock formation of plasmid pMEA300 (Vrijbloed et al., 1995). The TolA protein of E. coli was also shown to possess repetitive sequences (KAAAD $5 \times$, KAAAE $6 \times$, KAEA $4 \times$ ). These repetitive sequences might enable TolA to form an amphipathic helix spanning the membrane (Levengood et al., 1991).

The TolA protein was shown to interact with the other Tol proteins TolQ and TolR, probably forming a channel through the outer and inner membrane for the uptake of colicins and single-stranded phage DNA (Click \& Webster, 1998). The similarity of SpdB2 to the TolA protein allows speculation on the function of the Spd proteins. The Streptomyces SpdB2 protein might interact with the other Spd proteins in a similar manner to support translocation of the plasmid, resulting in the spreading of the plasmids into the mycelial compartments.

Whereas the spd genes of the other Streptomyces RCR plasmids lie in each case downstream of the main transfer gene tra (Kendall \& Cohen, 1987; Hagège et al., 1993; Kataoka et al., 1994a ; Servin-Gonzales, 1995), the putative spd genes of pSG5 show a different location. 
They lie upstream of tra and its promoter, thus separating tra from the divergently transcribed regulatory gene traR. Therefore, they are not cotranscribed with $t r a$. In addition, the upstream region of $s p d B 3$ did not reveal any promoter activity in the direction of $s p d B 3$, whereas strong activity was found for the upstream regions of rep, traB, traR, ORF193 and prg (Table 2). The lack of any promoter activity upstream of the putative spd operon explains the absence of pock formation during transfer of pSG5. An interesting question is whether insertion of a promoter in front of the pSG5 spd genes renders pSG5 pock-forming.

Functions of the pSG5-encoded genes were investigated by analysing the phenotype of various $\operatorname{Tn} 5$ insertions in pSG5 which were obtained during the identification of the pSG5 minimal replicon (Muth et al., 1988). Since the $\mathrm{Tn} 5$ insertions had negative effects on the stability of the mutagenized bifunctional plasmids, the $E$. coli part (pSLE41) of pSW344E (Muth et al., 1988) was deleted by EcoRI restriction. The resulting plasmids, which comprised the original pSG5 plasmid carrying a Tn5 insertion, were more stable than the rather large $(24 \mathrm{~kb})$ pSW344:: Tn5 plasmids.

Only inactivation of $\operatorname{traB}$ significantly affected selftransmissibility of pSG5. The Tn 5 insertion within $\operatorname{traB}$ reduced conjugative transfer of the pSG5 derivative to $10^{-5}$, a rate also obtained with the minimal replicon of pSG5 containing only rep (Muth et al., 1995). This is in contrast to other plasmids, where inactivation or deletion of tra results in transfer rates of $10^{-7}$ or less (Kieser et al., 1982; Hagège et al., 1993; Kataoka et al., 1994a; Servin-Gonzales et al., 1995).

The TraB protein of pSG5 as well as the Tra proteins of the other Streptomyces RCR plasmids showed the highest similarities to the proteins of the SpoIIIE/FtsK family (Begg et al., 1995; Wu et al., 1995). They are of about the same size, have a similar protein structure with predicted $\mathrm{N}$-terminal transmembrane helices, and have been located within the membrane (Tra of pIJ101: Pettis \& Cohen, 1996; and TraB of pSN22: Kosono et al., 1996) and membrane septum (SpolIIE: Wu \& Errington, 1997), respectively. They have conserved sequence motifs in the C-terminus (Begg et al., 1995) with an ATP-binding site, which was shown to be essential for the function of TraB from pSN22 (Kosono et al., 1996) and SpoIIIE (Wu \& Errington, 1997). These similarities suggest that the Tra protein has a similar role in the plasmid transfer as that reported for SpoIIIE in the translocation of the chromosome from the mother cell to the forespore. Several SpoIIIE monomers were shown to integrate into the septum with their $\mathrm{N}$-termini, forming a ring-like structure. The C-terminus of SpoIIIE, which was localized in the cytoplasm, probably interacts with the chromosome of $B$. subtilis to support its translocation into the forespore (Wu et al., 1995; Wu \& Errington, 1997).

The similarity of the SpoIIIE/FtsK protein to the Streptomyces Tra protein could also explain how the transfer of the pSG5 minimal replicon could proceed without a Tra protein. Under certain conditions, the chomosomal SpoIIIE homologue of S. lividans might be able to replace (with low efficiency) the plasmid-encoded Tra protein and hence translocate the pSG5 derivative to the recipient. Alternatively, the pSG5 minimal replicon could be mobilized by an unidentified, probably integrated plasmid, carrying transfer functions.

In contrast to the tra genes of the other Streptomyces RCR plasmids (Kendall \& Cohen, 1987; Hagege et al., 1993; Kataoka et al., 1994a; Servin-Gonzales et al., $1995)$, the traB gene of pSG5 does not represent a kill function. This corresponds to the observation that a Tn5 insertion in traR of pSG5 did not result in cell death. The reason for the toxic effect of tra overexpression on Streptomyces is unclear. The incorporation of large amounts of Tra into the membrane may be responsible for the lethal effect, possibly by interfering with membrane integrity. This is supported by the fact that the N-terminal half of the pIJ101 tra gene (Kieser $e t$ al., 1982; Kendall \& Cohen, 1988), which encodes the hydrophobic, most likely membrane-associated part of Tra, is sufficient for killing. Nevertheless, expression of pSG5 traB was shown to affect differentiation. Sporulation of $S$. lividans carrying the traB-encoding plasmid pJG5 was temporarily retarded, but not completely inhibited. An effect of a Streptomyces RCR plasmid gene on differentiation has been previously reported for Spi from the Streptomyces azureus plasmid pSA1.1 (Tomura et al., 1993). The deletion of the small $40 \mathrm{bp}$ Bam HI fragment during the construction of the pSA1.1 derivatives (Tomura et al., 1993) might have inactivated the TraR homologue of pSA1.1, leading to overexpression of spi, resulting in the inhibition of sporulation. Since spi was also shown to be involved in conjugal transfer and pock formation, and since sequence analysis of the spi gene revealed similarity to the $B$. subtilis SpollIE protein, the Spi protein of pSA1.1 most probably represents the Tra homologue. Thus, the tra homologue (spi) of plasmid pSA1.1 conferred a similar phenotype as the tra gene of pSG5. Sporulation was (temporarily) inhibited, but the host was not killed.

In all Streptomyces RCR plasmids, transcription of the main tra gene is regulated by TraR/KorA, a negative regulator of the GntR family (Haydon \& Guest, 1991). With the exception of the integrative plasmid pSAM2 from Streptomyces ambofaciens, where korSA is transcribed in the same direction as rep (Hagège et al., 1993), the traR gene is in all cases divergently transcribed to the tra gene. TraR was shown to bind to the intergenic region between traR and tra, which contains the overlapping promoters (Stein et al., 1989; Kataoka et al., 1994b). In pSN22 TraR binds to so-called tre boxes, which comprise characteristic 12 bp repeats (Kataoka et al., 1994b). Such repeats have been also found in the intergenic region of the pJV1 traR and tra genes. In pSG5 the traR and traB genes are not located side by side. Neither the putative promoter regions of $t r a R$ nor the promoter region of $\operatorname{traB}$ contain sequences with similarity to tre boxes or other striking repeats. Nevertheless, traB is negatively regulated by the TraR protein. 
The presence of traR clearly repressed transcription of the $\operatorname{tra} B$ promoter.

Since none of the characteristic functions of other bacterial transfer systems, such as a system for establishing cell-to-cell contact (Manning \& Achtmann, 1979; Clewell, 1993), a specific nicking enzyme (Ilyina \& Koonin, 1992; Pansegrau et al., 1990), or an oriT as a replication origin for the synthesis of a single-stranded plasmid molecule (Wilkins \& Lanka, 1993; Climo et al., 1996), could be found on a Streptomyces RCR plasmid, Streptomyces seem to have evolved a unique system completely different from the other bacterial transfer systems. The similarity of the main transfer protein Tra to the B. subtilis SpoIIIE protein suggests that conjugative plasmid transfer in Streptomyces resembles more the translocation system of the chromosome during cell division and sporulation.

\section{ACKNOWLEDGEMENTS}

This work was supported by the Deutsche Forschungsgemeinschaft (Mu 1219/1-2). We thank M. Labes for critical reading of the manuscript.

\section{REFERENCES}

Allison, S. L. \& Phillips, A. T. (1990). Nucleotide sequence of the gene encoding the repressor for the histidine utilization genes of Pseudomonas putida. J Bacteriol 172, 5470-5476.

Altschul, S. F., Gish, W., Miller, W., Myers, E. W. \& Lipmann, D. J. (1990). Basic local alignment search tool. J Mol Biol 215, 403-410.

Begg, K. J., Dewar, S. J. \& Donachie, W. D. (1995). A new Escherichia coli cell division gene, ftsK. J Bacteriol 177, 6211-6222.

Bibb, M. J. \& Hopwood, D. A. (1981). Genetic studies of the fertility plasmid SCP2 and its SCP2* variants in Streptomyces coelicolor A3(2). J Gen Microbiol 126, 427-442.

Bibb, M. J., Freeman, R. F. \& Hopwood, D. A. (1977). Physical and genetical characterization of a second sex factor, SCP2, for Streptomyces coelicolor A3(2). Mol Gen Genet 154, 155-166.

Bullock, W. O., Fernandez, J. M. \& Short, J. M. (1987). XL1-Blue, a high efficiency plasmid transforming recA Escherichia coli strain with beta-galactosidase selection. Focus 5, 376-378.

Clewell, D. B. (1993). Sex pheromones and the plasmid encoded mating response in Enterococcus faecalis. In Bacterial Conjugation, pp. 349-367. Edited by D. B. Clewell. New York: Plenum.

Click, E. M. \& Webster, R. E. (1998). The TolQRA proteins are required for membrane insertion of the major capsid protein of the filamentous phage $\mathrm{f} 1$ during infection. J Bacteriol 180, 1723-1728.

Climo, M. W., Sharma, V. K. \& Archer, G. L. (1996). Identification and characterization of the origin of conjugative transfer (oriT) and a gene (nes) encoding a single-stranded endonuclease on the staphylococcal plasmid pGO1. J Bacteriol 178, 4975-4983.

Frost, L. S., Ippen-Ihler, K. \& Skurray, R. A. (1994). Analysis of the sequence and gene products of the transfer region of the $F$ sex factor. Microbiol Rev 58, 162-210.

Gross, J. D. \& Caro, L. G. (1966). DNA transfer in bacterial conjugation. J Mol Biol 16, 269-284.

Haase, J., Lurz, R., Grahn, M., Bamford, D. H. \& Lanka, E. (1995). Bacterial conjugation mediated by plasmid RP4: RSF1010 mobi- lization, donor specific phage propagation, and pilus production require the same Tra2 core components of the proposed DNA transport complex. J Bacteriol 177, 4779-4791.

Hagège, J., Pernodet, J.-L., Sezonov, G., Gebraud, C., Friedmann, A. \& Guérineau, M. (1993). Transfer functions of the conjugative integrating element pSAM2 from Streptomyces ambofaciens: characterization of a kil-kor system associated with transfer. $J$ Bacteriol 175, 5529-5538.

Haydon, D. J. \& Guest, J. R. (1991). A new family of bacterial regulatory proteins. FEMS Microbiol Lett 63, 291-295.

Hernando, Y., Palacios, J. M., Imperial, J. \& Ruiz-Argueso, T. (1995). The hypBFCDE operon from Rhizobium leguminosarum biovar viciae is expressed from an Fnr-type promoter that escapes mutagenesis of the fnrN gene. J Bacteriol 177, 5661-5669.

Hofmann, K. \& Stoffel, W. (1993). TMbase - a database of membrane spanning proteins segments. Biol Chem Hoppe-Seyler 347, 166.

Hopwood, D. A. \& Kieser, T. (1993). Conjugative plasmids of Streptomyces. In Bacterial Conjugation, pp. 293-311. Edited by D. B. Clewell. New York : Plenum.

Hopwood, D. A., Kieser, T., Wright, H. M. \& Bibb, M. J. (1983). Plasmids, recombination and chromosome mapping in Streptomyces lividans TK66. J Gen Microbiol 129, 2257-2265.

llyina, T. \& Koonin, E. V. (1992). Conserved sequence motifs in the initiator proteins for rolling-circle DNA replication encoded by diverse replicons from eubacteria, eucaryotes and archaebacteria. Nucleic Acids Res 20, 3279-3285.

Kataoka, M., Kiyose, Y. M., Michisuji, Y., Horiguchi, T., Seki, T. \& Yoshida, T. (1994a). Complete nucleotide sequence of the Streptomyces nigrifaciens plasmid, pSN22: genetic organization and correlation with genetic properties. Plasmid 32, 55-69.

Kataoka, M., Kosono, S., Seki, T. \& Yoshida, T. (1994b). Regulation of the transfer genes of Streptomyces plasmid pSN22: in vivo and in vitro study of the interaction of $\mathrm{TraR}$ with promoter regions. J Bacteriol 176, 7291-7298.

Kendall, K. J. \& Cohen, S. N. (1987). Plasmid transfer in Streptomyces lividans: identification of a kil-kor system associated with the transfer region of pIJ101. J Bacteriol 169, 4177-4183.

Kendall, K. J. \& Cohen, S. N. (1988). Complete nucleotide sequence of the Streptomyces lividans plasmid pIJ101 and correlation of the sequence with genetic properties. J Bacteriol 170, 4634-4651.

Kieser, T., Hopwood, D. A., Wright, H. M. \& Thompson, C. J. (1982). pIJ101, a multi-copy broad host-range Streptomyces plasmid: functional analysis and development of DNA cloning vectors. Mol Gen Genet 185, 223-238.

Kingsman, A. \& Willetts, N. (1978). The requirements for conjugal DNA synthesis in the donor strain during $\mathrm{F}$ lac transfer. $J \mathrm{Mol}$ Biol 122, 287-300.

Kosono, S., Kataoka, M., Seki, T. \& Yoshida, T. (1996). The TraB protein, which mediates the intermycelial transfer of the Streptomyces plasmid pSN22, has a functional NTP-binding motif and is localized to the cytoplasmic membrane. Mol Microbiol 19, $397-405$.

Levengood, S. K., Beyer, W. F., Jr \& Webster, R. E. (1991). TolA : a membrane protein involved in colicin uptake contains an extended helical region. Proc Natl Acad Sci USA 88, 5939-5943.

Manning, P. \& Achtmann, M. (1979). Cell-to-cell interactions in conjugating Escherichia coli: the involvement of the cell envelope. In Bacterial Outer Membranes: Biogenesis and Functions, pp. 409-448. Edited by M. Inouye. New York: Wiley.

Muth, G., Wohlleben, W. \& Puhler, A. (1988). The minimal replicon of the Streptomyces ghanaensis plasmid pSG5 identified 
by subcloning and Tn5 mutagenesis. Mol Gen Genet 211, 424-429.

Muth, G., Nußbaumer, B., Wohlleben, W. \& Püler, A. (1989). A vector system with temperature-sensitive replication for gene disruption and mutational cloning. Mol Gen Genet 219, 341-348.

Muth, G., Farr, M., Hartmann, V. \& Wohlleben, W. (1995). Streptomyces ghanaensis plasmid pSG5: nucleotide sequence analysis of the self-transmissible minimal replicon and characterization of the replication mode. Plasmid 33, 113-126.

Muth, G., Frese, D., Kleber, A. \& Wohlleben, W. (1997). Mutational analysis of the Streptomyces lividans recA gene suggests that only mutants with residual activity are viable. $\mathrm{Mol}$ Gen Genet 255, 420-428.

Pansegrau, W., Balzer, D., Kruft, V., Lurz, R. \& Lanka, R. (1990). In vitro assembly of relaxosomes at the transfer origin of plasmid RP4. Proc Natl Acad Sci USA 87, 6555-6559.

Pearson, W. R. \& Lipman, D. J. (1988). Improved tools for biological sequence comparison. Proc Natl Acad Sci USA 85, 2444-2448.

Pettis, G. S. \& Cohen, S. N. (1994). Transfer of the pIJ101 plasmid in Streptomyces lividans requires a cis-acting function dispensable for chromosomal gene transfer. Mol Microbiol 13, 955-964.

Pettis, G. S. \& Cohen, S. N. (1996). Plasmid transfer and expression of the transfer $(\mathrm{tra})$ gene product of plasmid pIJ101 are temporally regulated during the Streptomyces lividans life cycle. Mol Microbiol 19, 1127-1135.

Servin-Gonzales, L., Sampieri, A., Cabello, J., Galvan, L., Juarez, V. \& Castro, C. (1995). Sequence and functional analysis of the Streptomyces phaeochromogenes plasmid pJV1 reveals a modular organization of Streptomyces plasmids that replicate by rollingcircle. Microbiology 141, 2499-2510.

Solenberg, P. J. \& Baltz, R. H. (1994). Hypertransposing derivatives of the streptomycete insertion sequence IS493. Gene 147, 47-54.

Staden, R. \& McLachlan, A. D. (1982). Codon preference and its use in identifying protein coding regions in large DNA sequences. Nucleic Acids Res 10, 141-156.

Stein, D. S., Kendall, K. J. \& Cohen, S. N. (1989). Identification and analysis of transcriptional regulatory signals for the kil and kor loci of Streptomyces plasmid plJ101. J Bacteriol 171, 5768-5775.

Thompson, J. D., Higgins, D. G. \& Gibson, T. J. (1994). CLUSTAL w : improving the sensitivity of progressive multiple sequence alignment through sequence weighting, position-specific gap penalties and weight matrix choice. Nucleic Acids Res 22, 4673-4680.

Tomura, T., Kishino, H., Doi, K., Hara, T., Kuhara, S. \& Ogata, S. (1993). Sporulation-inhibitory gene in pock forming plasmid
pSA1.1 of Streptomyces azureus. Biosci Biotechnol Biochem 57, 438-443.

Volff, J. N. \& Altenbuchner, J. (1997). High frequency transposition of the Tn5 derivative $\operatorname{Tn} 5493$ in Streptomyces lividans. Gene 194, 81-86.

Vrijbloed, J. W., Van der Put, N. M. J. \& Dijkhuizen, L. (1995). Identification and functional analysis of the transfer region of plasmid pMEA300 of the methylotrophic actinomycete Amycolatopsis methanolica. J Bacteriol 177, 6499-6505.

Walker, J. E., Saraste, M., Runswick, M. J. \& Gay, N. J. (1982). Distantly related sequences in the $\alpha$ - and $\beta$-subunits of ATP synthase, myosin kinases and other ATP-requiring enzymes and a common nucleotide binding fold. EMBO J 1, 945-951.

Ward, J. M., Janssen, G. R., Kieser, T., Bibb, M. J. \& Buttner, M. J. (1986). Construction and characterization of a series of multicopy promoter-probe plasmid vectors for Streptomyces using the aminoglycoside phosphotransferase gene from $\mathrm{Tn} 5$ as indicator. Mol Gen Genet 203, 468-478.

Weiss, A. A., Johnson, F. D. \& Burns, D. L. (1993). Molecular characterization of an operon required for pertussis toxin secretion. Proc Natl Acad Sci USA 90, 2970-2974.

Wilkins, B. \& Lanka, E. (1993). DNA processing and replication during plasmid transfer between gram-negative bacteria. In Bacterial Conjugation, pp. 105-136. Edited by D. B. Clewell. New York: Plenum.

Wohlleben, W. \& Muth, G. (1993). Streptomyces plasmid vectors. In Plasmids, pp. 147-175. Edited by K. G. Hardy. Oxford: IRL Press.

Wright, F. \& Bibb, M. J. (1992). Codon usage in the $G+C$ rich Streptomyces genome. Gene 113, 55-65.

Wu, L. J. \& Errington, J. (1997). Septal localization of the SpollIE chromosome partitioning protein in Bacillus subtilis. EMBO J16, 2161-2169.

Wu, X. \& Roy, K. L. (1993). Complete nucleotide sequence of a linear plasmid from Streptomyces clavuligerus and characterization of its RNA transcripts. J Bacteriol 175, 37-52.

Wu, L. J., Lewis, P. J., Allmansberger, R., Hauser, P. M. \& Errington, J. (1995). A conjugation-like mechanism for prespore chromosome partitioning during sporulation in Bacillus subtilis. Genes Dev 9, 1316-1326.

Yu, T.-W. \& Hopwood, D. A. (1996). Ectopic expression of the Streptomyces coelicolor whiE genes for polyketide spore pigment synthesis and their interaction with the act genes for actinorhodin biosynthesis. Microbiology 141, 2779-2791.

Received 18 May 1998; revised 18 June 1998; accepted 24 June 1998. 